\title{
Offering older hospitalised patients the choice to die in their preferred place
}

\author{
David Jonathan Ahearn, ${ }^{1}$ Niamh Nidh, ${ }^{2}$ Arun Kallat, ${ }^{2}$ Yousouf Adenwala, ${ }^{2}$ \\ Surendra Varman ${ }^{2}$
}

${ }^{1}$ Department of Elderly Medicine, Wythenshawe Hospital, Manchester, UK ${ }^{2}$ Department of Elderly Medicine, Royal Bolton Hospital, Bolton, UK

\section{Correspondence to} Dr David Jonathan Ahearn, Department of Elderly Medicine, Wythenshawe Hospital, Southmoor Road, Manchester, UK; davidjahearn@gmail.com

Received 25 May 2012 Revised 15 September 2012 Accepted 13 October 2012 Published Online First 9 November 2012
To cite: Ahearn DJ, Nidh N, Kallat $\mathrm{A}$, et al. Postgrad Med J 2013, 89, 20-24.

\begin{abstract}
Background A significant proportion of older people state a preference to die at home. However, the vast majority of people in hospital recognised as dying subsequently die there.

Objectives To identify the proportion of older people dying in hospital where the possibility of ending life elsewhere was explored. To identify factors that could support hospital staff to enable patients' wishes to be met.
\end{abstract}

Methods Retrospective case-note review of 100 older patients ( $>75$ years) who died during 2009 in an English Hospital.

Results Age range 75-97 years. Time from admission to death ranged from 0-118 days (median 8.5). $16 \%$ died within the first $48 \mathrm{~h}$, rising to $30 \%$ for those from care homes. In only 8 patients was a potential alternative place of death discussed. Although subjective, in 10 patients it was considered admission could have been avoided through Advance Care Planning (ACP) to allow patients with poor prognosis to die in their normal place of residence or a hospice. $55 \%$ of Do-NotAttempt-Resuscitation orders were made within $48 \mathrm{~h}$ of admission. 38\% were commenced on the Liverpool Care Pathway (LCP), 1-504 $\mathrm{h}$ before death (median 16).

Conclusions In few cases are the preferred places of death discussed in older people who die in our hospital. Although hospital admission was largely appropriate, in a minority judicious ACP could have avoided death in hospital. We recommend (1) increased use of ACP, with appropriate practicalities planned in advance (2) widescale introduction of the 'Rapid Discharge Home of the Dying Patient pathway' (3) routinely discussing preferred place of death in appropriate key situations (eg, discussion of resuscitation status or commencing the LCP).

\section{INTRODUCTION}

It has been shown that the proportion of older people dying in hospital is rising. ${ }^{1}$ Not all older people wish to die at home due to concerns such as being a burden, the availability of adequate symptom relief, or a dislike of the need for carers in the home. ${ }^{2}$ However, it has been reported in a community based sample that nearly four-fifths of those aged 65-85 years and just under half of those 85 years or older would choose to die at home. ${ }^{3}$ In a study of those 65 years or older recently hospitalised with cardiac or respiratory problems, $47 \%$ of those expressed a preference to die at home $;^{4}$ however, it is recognised that nearer the time of death views of place of death can change. ${ }^{5}$

This issue is recognised at a national level. The UK National End of Life Care Strategy recognises that a significant proportion of people do not die in their preferred place and makes key recommendations which include identifying people approaching the end of life, care planning, co-ordinating care and providing rapid access to services. ${ }^{6}$

Depending on the needs of the individual in question a rapid supported discharge may be appropriate to the patient's home (typically with the care of a partner or children), a hospice, or a care home accredited by the Gold Standards Framework. ${ }^{7}$

There are many problems inherent in discharging a dying patient from hospital. Evidence suggests older people are less likely to be known to Specialist Palliative Care teams and there may be inequitable access to hospice services. ${ }^{8}$ Practicalities are key and delays in providing equipment such as mattresses or setting up new or increased care packages have been shown to be contributory factors to patients dying in hospital rather than elsewhere. ${ }^{9}$

Emerging strategies such as the 'Liverpool Integrated Care Pathway for the Rapid Discharge Home of the Dying Patient ${ }^{10}$ attempt to address these issues. However, such measures require prompt co-ordination of social services, palliative care teams, general practitioners, district nurses and relatives' families or significant others. This document aims to facilitate medical and nursing palliative care from hospital to community in a seamless and timely manner, and can act as a continuation of in-hospital end of life care. A criterion for use is that family are aware that social/supportive care and equipment may not fully be in place (due to the urgency of the plan).

It is recognised that some patients admitted to hospital have little to gain from such an admission, and indeed it may be distressing or against the wishes of the patient. ${ }^{11}$ Advance Care Planning (ACP) including Preferred Priorities of Care forms allow decisions to be made that reflect the views of patients and relatives, and aim to avoid certain courses of action that may be of little benefit. ${ }^{12}$ For example, terminally ill care home residents often fall unwell at night when the patient's general practitioner and notes are unavailable, family may not be contactable, and care home staff may be junior and unsupported. Without documented ACP, it is almost inevitable that such individuals will be transferred to an acute care facility, even if care in the existing place of residence is preferred and more appropriate. Doctors have a key role to play in instituting ACP as they come in frequent contact with many of those who have most to gain from it for example, at diagnosis, when facilitating 
discharge from hospital (often with a new diagnosis, or to a new place of care), or as part of a community service.

The aim of our study was to perform a retrospective analysis of those who have died in hospital to identify the proportion where the possibility of dying at home was explored. A further objective was to identify factors that could support hospital staff to enable patients' wishes, by collecting data on key time points during the hospital stay that could help aid future planning in this area. These included the usage and timing of Do Not Attempt Resuscitation (DNAR) orders, and observing the duration before death the Liverpool Care Pathway (LCP) was initiated (where used). In addition, an assessment was made about whether the use of ACP prior to acute decline could have led to a more appropriate alternative to acute hospital admission being considered.

\section{METHODS}

\section{Design}

We performed a retrospective study of the case notes of 100 randomly selected patients meeting the study inclusion criteria. Due to a lack of previous work in this area to calculate variability of this descriptive data, power calculations were not possible. One hundred patients was agreed to be sufficient to reduce bias from a low sample size without placing excess burden on resources. An initial list of patients meeting the criteria was generated from hospitals admission data. The hospital audit department subsequently provided 100 notes selected from random from this list. Data collection was approved by the Royal Bolton Hospitals NHS Trust as part of service improvement work. As this was a retrospective review with no intervention, ethical approval was not deemed necessary.

\section{Study cohort}

We studied patients 75 years or older at the time of admission who died during 2009 in the Royal Bolton Hospital. Further details of the Royal Bolton Hospital are given in box 1. All patients were emergency admissions under the care of a consultant in the Department of Medicine at the time of death. Patients were admitted as an emergency either via the Emergency Department or a general practitioner to a Medical Assessment Unit with most patients subsequently transferred to a General Adult or Elderly Medical Ward. All patients admitted as an emergency aged greater than or equal to 75 years who

\section{Box 1 Setting: Royal Bolton Hospital}

- The Royal Bolton Hospital is a large and busy District General Hospital (678 beds) in North-West England serving a catchment area of 250000 . The Medical Assessment Unit typically admits between 40 and 60 patients per day aged 16 years and over with a wide spectrum of acute medical problems. In 2009 the hospital admitted 15969 patients to the Department of Medicine, of which 4945 (30.97\%) were over 75. Patients are admitted to either specialist acute wards or Elderly Medical wards depending on the anticipated needs of the patient. Specialist Palliative Care advice is available on a referral basis from nursing or medical colleagues. A hospice is situated locally although this is not large enough to accept all dying patients. The Liverpool Care Pathway is widely used for in-patients believed to be in the final days of life. died under the care of a General Internal Medicine physician or Geriatrician were included in the initial list with no exclusion criteria.

\section{Data analysis}

A paper-based case note review proforma was constructed by the study team to collect data including demographics, normal place or residence, co-morbidity, reason for admission, cause of death, usage and timing of DNAR orders and/or the LCP, and information about whether the issue of choosing an alternative place of death was considered. Medical and nursing notes were fully reviewed by a team of five geriatricians (three consultants and two specialty registrars); $60 \%$ were reviewed by consultants.

Notes were also assessed by the team to see if ACP prior to the acute decline could have triggered a more appropriate course of action than admission to hospital, such as transfer to a hospice or palliative care at home or in a care home. There are no standard guidelines as to what constitutes an inappropriate admission'. Such decisions involved an element of subjectivity but we focussed on individuals where ACP may have triggered an alternative course of action to hospital admission, for example, for those known to be in the final stages of life, or those admitted for treatment which could be foreseen to be unlikely to lead to an improvement in condition.

The data was entered into SPSS V.16.0 (SPSS Inc., 2007) and analysed by the research team.

\section{RESULTS}

\section{Demographics}

Patients ranged in age from 75-97 years (median 84 years). Prior to admission, 64 lived at home (of which 23 had formal carers visiting at least daily); 27 lived in care homes. Time to death ranged from 0-118 days (median 8.5) with 16\% dying within $48 \mathrm{~h}$ of admission, rising to $30 \%$ for those from care homes.

\section{Timing of key points during admission; usage of DNAR orders and the Liverpool Care Pathway}

This is detailed in table 1.94 patients had had DNAR orders completed before the time of death. Initially, 56\% of DNAR orders were signed by a consultant, $38 \%$ by a middle grade doctor, and $6 \%$ by junior medical staff. Ultimately $72 \%$ were signed by a consultant. In $55 \%$ of cases this was made on the day of admission or the day after. If those dying within $48 \mathrm{~h}$ of admission are excluded, this figure was $42 \%$. No patterns in timing of DNAR usage (as a proportion of the duration of stay) could be identified in the remaining $58 \%$ of patients.

Thirty-eight percent of patients had been commenced on the LCP prior to death. This was commenced between 1 and $504 \mathrm{~h}$ before death, median $12 \mathrm{~h}$. Ten per cent of patients were seen by the Palliative Care team (nursing or medical) prior to death.

\section{Considering alternative places of death}

In 92 patients there was no documented evidence that a potential alternative place of death to hospital was discussed with either the patient or his/her family.

The reviewers considered that in 10 patients, if ACP had occurred prior to acute decline, a better alternative to acute hospital admission could have been considered, thus allowing patients with poor prognosis to die in their normal place of residence or a hospice. Some examples are listed in box 2 . 
Table 1 Timing of key points throughout hospital admission in older patients who die in hospital

\begin{tabular}{|c|c|c|c|c|c|c|}
\hline & $\begin{array}{l}\text { Number of } \\
\text { patients }\end{array}$ & Range & $\begin{array}{l}\text { Lower } \\
\text { quartile }\end{array}$ & Median & $\begin{array}{l}\text { Upper } \\
\text { quartile }\end{array}$ & Comment \\
\hline Time from admission to death (days) & 100 & $0-118$ & 3 & 8.5 & 17.5 & \\
\hline Time from admission to Do-Not-Resuscitate order (days) & 94 & $0-84$ & 0 & 1 & 6 & $\begin{array}{l}\text { In } 55 \% \text { DNAR order implemented on day } \\
\text { of admission or the day after }\end{array}$ \\
\hline $\begin{array}{l}\text { Time from admission to Do-Not-Resuscitate order if those } \\
\text { dying within } 48 \mathrm{~h} \text { of admission excluded (days) }\end{array}$ & 84 & $0-84$ & 0 & 2 & 6 & $\begin{array}{l}\text { In } 42 \% \text { DNAR order implemented on day } \\
\text { of admission or the day after }\end{array}$ \\
\hline Time to death after Do-Not-Resuscitate order made (days) & 94 & $0-50$ & 1 & 4 & 9 & \\
\hline $\begin{array}{l}\text { Time to death from commencement on Liverpool Care } \\
\text { Pathway (LCP) (hours) }\end{array}$ & 38 & $1-504$ & 5 & 12 & 46 & $\begin{array}{l}\text { In } 71 \% \text { of the patients in whom the LCP } \\
\text { was started, it was commenced less than } \\
24 \mathrm{~h} \text { before death }\end{array}$ \\
\hline
\end{tabular}

DNAR, Do Not Attempt Resuscitation.

\section{DISCUSSION}

This study raises several issues of relevance to clinicians. In our study, we found dying hospitalised patients' preferred places of death were discussed in only a minority of cases. DNAR orders were instituted in most patients, a median of 4 days before death. This potentially provides an opportunity to discuss preferred place of death. In a significant minority, it was considered that if ACP had been in place an alternative to hospital admission could have been more appropriate.

For many patients it may not be feasible or appropriate for a dying older patient to have a supported discharge from hospital due to patient choice or difficulty in providing care or equipment. ${ }^{4} 589$ In addition, cognitive impairment is more frequent in older people, and they are less likely to have an able-bodied carer dwelling at home; a previous study showed over a third of older people dying in hospital lived alone with around a fifth having social services involvement. ${ }^{13}$ However, we believe that in significant numbers the opportunity is not being considered and facilitated where it is desired. Not all conversations about a potential alternative place of death may be recorded in case notes. However, our findings imply that the consideration of alternative places of death is not occurring frequently.

'A failure to take responsibility for enabling people to return home to die if that is their wish' has been cited as a barrier to

Box 2 Examples of patients where the reviewers believed that with Advance Care Planning (ACP) alternatives to acute hospital admission could have been considered

Eighty-two year old male with advanced vascular dementia admitted due to a progressive failure to eat or drink in the absence of acute illness. Nursing home resident, fully dependent for activities of daily living and unable to verbally communicate due to aphasia. With ACP a decision to provide symptom control in the Nursing Home may have been considered more appropriate than transfer to acute hospital.

- Seventy-eight year female with widespread metastatic bowel cancer under the care of community palliative care team. Patient was discharged only 2 days prior to readmission for palliative care at home. Patient was readmitted with multiple secretions (treated as a lower respiratory tract infection) and symptoms of bone pain and died approximately $12 \mathrm{~h}$ later. No ACP discussions documented during previous admission, the option to die at home or be transferred to the hospice may have been more appropriate. good palliative care for older people in acute settings. ${ }^{14}$ Reasons for this may include a lack of awareness of supported home discharge as a possibility among staff, patients and relatives, when hospice transfer is not an option. This may be reflected in the low rate of referral to Specialist Palliative care services. Indeed in our own unit where the Rapid Discharge Home of the Dying Patient pathway is available and supported by the Palliative Care team, awareness was lacking among virtually all medical and nursing staff, junior and senior. Similarly, awareness of the palliative care services in the community provided largely by District Nurses, backed up General Practitioners and Palliative Care services, may be lacking. These issues must be addressed as a priority.

Previous work has shown that discussions about death with older in-patients recognised as dying occur infrequently. ${ }^{11}$ However, if these issues are not discussed with patients and families then a patient's desire to die out of hospital is unlikely to be considered and fulfilled where possible.

A further barrier to discharge of a 'dying' patient is a lack of recognition that the patient has entered the final stages of life that is, the time where further life-saving or life-prolonging treatment is no longer indicated. Our figures show that the LCP (where commenced) is enacted only a median of $12 \mathrm{~h}$ prior to death, at which point a discharge from hospital is logistically difficult. Recognition of dying patients is notoriously difficult, especially in those with a diagnosis other than cancer $^{15}$ and although guidance exists ${ }^{16}$ much more research is needed in this area. We would argue that in some of our reviewed cases it could have been foreseen earlier than documented that the probability of survival from the current illness was slim. If it was known in advance that a patient's preferred option was to die out of hospital this could have a bearing on the continuation of treatment deemed to have a low probability of success, or even prompt supported discharge to continue with treatment such as antibiotics and home oxygen. Again, sensitive discussion with relatives and families are necessary to know if this is a desired or feasible.

As over 9 in 10 patients had a DNAR order in place prior to death, this may be a key opportunity to discuss preferred place of death where deemed appropriate. It is however known that contrary both to policy and good practice that decisions around resuscitation status often occur without involving patients and (to a lesser extent) relatives ${ }^{13}{ }^{17}$ thus potentially missing an opportunity to have this important discussion. The conversation can emphasise that death is not necessarily expected, and that if a patient deteriorated further then further discussions would occur. We suggest a statement routinely asked (at the discretion of the physician) such as 'If your condition was to get worse 
Main messages

- In older patients who die in hospital patients' preferred places of death were rarely asked or considered.

- More routinely asking about patients' preferred place of death and increasing hospital staff awareness of community palliative care services should enable more older people to die in their preferred setting.

- When discussing resuscitation status (even if the patient is not considered to be dying) or commencing the Liverpool Care Pathway can be key times to enquire about patients' preferred place of death.

- In those living in the community who have a life-limiting illness, discussions should be considered before an acute illness to institute Advance Care Planning where appropriate.

and it seemed as if you may not get better, do you have a preferred place to spend your final days?'. In patients unable to provide a coherent answer relatives may be able to state any previously specified views of the patient, or even draw attention to advance directives. In our own hospital we have proposed adding this question to the DNAR form and this is currently under consideration.

Avoiding admission to hospital in the first place in patients deemed to have a poor prognosis, while contentious, is a recognised strategy using ACP. In our sample, although subjective, we deemed that in at least $10 \%$ of patients (a significant minority) an alternative to hospital admission could have been considered (box 1). For this to occur realistically and in a consistent manner, discussions with the patient, family and others (eg, care home staff) need to have occurred prior to acute decline. As above, early communication is paramount if the wishes of those whose lifespan is limited are to be respected.

Clearly, the results from this study must be taken in context. There are limitations with any retrospective study, particularly those that involve case notes rather than verbal discussions as not all information may not be entered into case notes. The views of a patient or their relatives (if known) may not be documented. Pertinent to the question about whether hospital

\section{Current research questions}

- Would routinely asking about preferred place of death at the time of discussions of resuscitation status help plan to allow patients to die at home where appropriate? What would the views and experiences of patients and staff to such a measure be?

- What other barriers exist that prevent healthcare staff from discussing alternative places to die in older hospitalised patients? Are staff fearful of broaching these sensitive issues?

- Since previous research was performed, have the practical barriers for example, rapid availability of care packages or equipment (such as mattresses) improved or worsened?

- Why is Advance Care Planning still not performed as a matter of course in people known to have life-limiting illnesses?

\section{Key References}

- The Gold Standards Framework. GSF in Care Home. http:/l www.goldstandardsframework.org.uk/GSFCareHomes (accessed 28 Aug 2012).

- Townsend J, Frank AO, Fermond D, et al. Terminal cancer care and patients' preferences for place of death: a prospective study. BMJ 1990;301:415-17.

- Murphy D, Ellershaw J, Jack B, et al. The Liverpool Care Pathway for the rapid discharge home of the dying patient. J Integr Care Pathw 2004;8:127-8.

- Detering KM, Hancock AD, Reade MC, et al. The impact of advance care planning on end of life care in elderly patients: randomized controlled trial. BMJ 2010;340:c1345.

admission could have been avoided, the lack of a standard definition and an unknown inter-rater reliability indicate the calculated figure should be treated with caution. Although covering an important topic in a typical District General Hospital, the study focuses on patients in one area and different policies and protocols in other areas may affect the results if the study is repeated elsewhere.

Future work must focus on the reasons for the findings of this study. We suggest routinely asking about preferred place of death at key points such as discussing a DNAR order. However research is required to see if such a move would be acceptable (to patients, relatives and staff), as well as determining any change in the outcome of meeting patients' wishes. More extensive work is needed to determine barriers to considering discharge or transfer of dying patients, be these attitudinal, a lack of awareness of options available, or practical obstacles that can be overcome in a timely fashion.

Contributors DA developed the research question and wrote the first draft of the paper. All authors were involved in data collection. DA and NN were involved in data input. All authors were involved in data interpretation. All authors were involved in amending the initial draft and approving the submitted version.

Funding None.

\section{Competing interests None.}

Provenance and peer review Not commissioned; externally peer reviewed.

Data sharing statement Further data was collected from the notes of the patients reviewed as part of a general mortality review looking at factors that could have affected deceased older patients' outcomes and experiences following admission to hospital. None of these are directly relevant to this study.

\section{REFERENCES}

1 Ahmad S, O'Mahony MS. Where older people die: a retrospective population-based study. Q J Med 2005;98:865-70.

2 Gott M, Seymour J, Bellamy G, et al. Older peoples' views about home as a place of care at the end of life. Palliat Med 2004;18:460-7.

3 Abarshi E, Echteld MA, Van Den Block L, et al. The oldest old and GP end-of life care in the community: a nationwide study. Age Ageing 2010;39:716-22.

4 Fried TR, van Doorn C, O'Leary JR, et al. Older person's preferences for site of terminal care. Ann Intern Med 1999;131:109-12.

5 Agar M, Currow DC, Shelby-James TM, et al. Preference for place of care and place of death in palliative care: are these different questions? Palliat Med 2008;22:787-95

6 Department of Health. End of Life Care Strategy. 2008. http://www. endoflifecareforadults.nhs.uk/assets/downloads/pubs_EoLC_Strategy_1.pdf (accessed 28 Aug 2012).

7 The Gold Standards Framework. GSF in Care Home. http://www goldstandardsframework.org.uk/GSFCareHomes (accessed 28 Aug 2012).

8 Gardiner C, Cobb M, Gott M, et al. Barriers to providing palliative care for older people in acute hospitals. Age Ageing 2011;40:233-8. 
9 Townsend J, Frank AO, Fermond D, et al. Terminal cancer care and patients' preferences for place of death: a prospective study. BMJ 1990;301:415-17.

10 Murphy D, Ellershaw J, Jack B, et al. The Liverpool Care Pathway for the rapid discharge home of the dying patient. J Integr Care Pathw 2004;8:127-8.

11 Partridge J. Why are nursing home residents sent in to hospital to die? Postgrad Med J 2008;84:281.

12 Detering $\mathrm{KM}$, Hancock $A D$, Reade MC, et al. The impact of advance care planning on end of life care in elderly patients: randomized controlled trial. BMJ 2010;340:C1345.

13 Twomey F, McDowell DK, Corcoran GD. End-of-life care for older patients dying in an acute general hospital-can we do better? Age Ageing 2007;36:462-4.
14 Gott M, Ingleton C, Gardiner C, et al. How to improve end of life care in acute hospitals. Nurs Older People 2009;21:26-9.

15 Ellershaw J, Ward C. Care of the dying patient: the last hours or days of life. BMJ 2003;326:30-4

16 The Gold Standards Framework. Prognostic Indicator Guidance version 5. http:// www.goldstandardsframework.org.uk/Resources/Gold\%20Standards\%20Framework/ General/Prognostic\%20Indicator\%20Guidance\%20\%20Final\%20Sept\%202011.pdf (accessed 28 Aug 2012).

17 McNamee J, O'Keeffee ST. Documentation of do-not-resuscitate orders in an Irish hospital. Ir J Med Sci 2004;173:99-101. 